\title{
Analytical approach for predicting fresh water discharge in an estuary based on tidal water level observations
}

\author{
H. Cai ${ }^{1}$, H. H. G. Savenije ${ }^{1}$, and C. Jiang ${ }^{2}$ \\ ${ }^{1}$ Department of Water Management, Faculty of Civil Engineering and Geosciences, Delft University of Technology, \\ Stevinweg 1, P.O. Box 5048, 2600 GA Delft, the Netherlands \\ ${ }^{2}$ School of Hydraulic, Energy and Power Engineering, Yangzhou University, Yangzhou, 225127, China \\ Correspondence to: H. Cai (h.cai@tudelft.nl)
}

Received: 22 May 2014 - Published in Hydrol. Earth Syst. Sci. Discuss.: 27 June 2014

Revised: 5 September 2014 - Accepted: 19 September 2014 - Published: 17 October 2014

\begin{abstract}
As the tidal wave propagates into an estuary, the tidally averaged water level tends to rise in landward direction due to the density difference between saline and fresh water and the asymmetry of the friction. The effect of friction on the residual slope is even more remarkable when accounting for fresh water discharge. In this study, we investigate the influence of river discharge on tidal wave propagation in the Yangtze estuary with specific attention to residual water level slope. This is done by using a one-dimensional analytical model for tidal hydrodynamics accounting for the residual water level. We demonstrate the importance of the residual slope on tidal dynamics and use it to improve the prediction of the tidal propagation in estuaries (i.e. tidal damping, velocity amplitude, wave celerity and phase lag), especially when the influence of river discharge is significant. Finally, we develop a new inverse analytical approach for estimating fresh water discharge on the basis of tidal water level observations along the estuary, which can be used as a tool to obtain information on the river discharge that is otherwise difficult to measure in the tidal region.
\end{abstract}

\section{Introduction}

Estuaries are water bodies that form the transition between an ocean (or sea) and a river. Their specific hydraulic behaviour is unique in that they are not merely a mixture of marine and a riverine signatures, experiencing both the effect of tides and of river discharge, but that they have a very specific hydraulic behaviour with a phase lag somewhere between that of a progressive and standing wave, a strongly deformed tidal wave and a residual water level slope due to the presence of a density gradient and the asymmetry of the friction between ebb and flood currents (e.g. Savenije, 2012). This asymmetry is even strengthened by river discharge. Due to the inherent funnel shape of estuaries, the effect of river discharge is much smaller near the estuary mouth, where the cross-sectional area is generally orders of magnitude larger than the cross-section of the river, but it can become dominant further upstream in the estuary, particularly during times when the river is in spate.

Due to the general dominance of tidal flows in the tidal region of an estuary, it is often difficult to determine the magnitude of the fresh water discharge accurately. Thus, discharge gauging stations are usually situated at locations outside the tidal region, even though there may be additional tributaries or drainage areas within the tidal region. Knowing the fresh water discharge within the tidal region, however, may be important for water resource assessment or flood hazard prevention (e.g. Madsen and Skotner, 2005; Erdal and Karakurt, 2013; Liu et al., 2014), or for the analyses of sediment supply (e.g. Syvitski et al., 2003; Prandle, 2004; Wang et al., 2008), or for irrigation or estimating the effect of water withdrawals on salt intrusion (e.g. MacCready, 2007; Gong and Shen, 2011; Zhang et al., 2012a), and for assessing the impacts of future climate change (e.g. Kukulka and Jay, 2003a, b; Moftakhari et al., 2013). Although it is possible to estimate river flow by upscaling the gauged part of a catchment, such an estimate may be inaccurate, especially in poorly gauged catchments or in high-precipitation coastal areas (Jay and Kukulka, 2003). 
It is noted that several forward models (determining tidal properties from fresh water discharge) have been presented to investigate the interaction between fresh water discharge and tide in estuaries (e.g. Dronkers, 1964; Leblond, 1978; Godin, 1985, 1999; Jay, 1991; Jay et al., 2011; Jay and Flinchem, 1997; Kukulka and Jay, 2003a, b; Horrevoets et al., 2004; Buschman et al., 2009; Cai et al., 2012b, 2014). Based on the tidal theory developed by Jay (1991), Jay et al. (2011), Jay and Flinchem (1997) and Kukulka and Jay (2003a, b), Jay and Kukulka (2003) used an inverse model (determining fresh water discharge from tidal properties) to hindcast river flows for a very high-flow year (1948) and for a lowflow year (1992) in Columbia River. The model was further successfully applied to estimate the history of inflow to San Francisco Bay using the available tidal records (Jay et al., 2005). Recently, Moftakhari et al. (2013), building on the earlier work by Jay and Kukulka (2003), revised the method of predicting fresh water discharge by including a quantification of uncertainties. However, such an approach is based on statistical and harmonic analyses without using an analytical relationship between the fresh water discharge and other controlling parameters (such as water level and tidal damping). In this paper, we aim to establish an analytical equation relating tidal wave propagation to the fresh water discharge from upstream. Besides the general interest of establishing an analytical relation between wave celerity, phase lag, velocity amplitude, tidal damping, residual slope and river discharge, this relationship can be of practical use to estimate, in an inverse way, river discharge on the basis of observed tidal water levels along the estuary axis. Of course our method also has its disadvantages. It requires an exponential shape (as is the case in alluvial estuaries), it requires that the $M_{2}$ is dominant over other tidal constituents, and there should be a measurable influence of the river discharge (river discharge and tidal discharge being within the same order of magnitude). It should also be realized that in convergent estuaries of infinite length there is no reflected wave (see also Jay, 1991), but that it is essentially a single wave moving in upstream direction with a phase shift that depends on convergence and damping (according to the phase lag Eq. T1 in Table 2).

The Yangtze estuary in China is used as an illustration of the analytical approach. The tidal dynamics of the Yangtze estuary was earlier investigated by Zhang et al. (2012b) using an analytical model proposed by Savenije et al. (2008). They calibrated their model on data observed during the dry season assuming that the effect of river discharge was negligible. In this paper, we elaborate on the analytical solutions proposed by Cai et al. (2014) and investigate the influence of residual water level on tidal dynamics, which is poorly known, especially during the wet season when there is strong river discharge. In the method section, we build on the analytical approach proposed by Cai et al. (2014) accounting for the effect of river discharge. The method consists of two parts. The first part still considers a fixed tidally averaged depth, while the second part involves an iterative procedure to account for the residual water level slope due to nonlinear friction. In Sect. 3, the analytical model is applied to the Yangtze estuary, and the way in which river discharge affects the tidal damping is discussed. Subsequently, we propose a new method to estimate fresh water discharge based on observed tidal water levels in the upstream part of an estuary. Finally, conclusions are drawn in Sect. 4.

\section{Method}

\subsection{Analytical model for tidal dynamics accounting for river discharge}

The basic geometric assumption of the analytical model is that the shape of alluvial estuaries can be descried by exponential functions of tidally average cross-sectional area, width and depth (e.g. Savenije, 2005, 2012):

$\bar{A}=\overline{A_{0}} \exp \left(-\frac{x}{a}\right)$,
$\bar{B}=\overline{B_{0}} \exp \left(-\frac{x}{b}\right)$,
$\bar{h}=\overline{h_{0}} \exp \left(-\frac{x}{d}\right)$,

where $x$ is the longitudinal coordinate directed landward, $\bar{A}, \bar{B}, \bar{h}$ are the tidally averaged cross-sectional area, stream width and flow depth, $a, b, d$ are the convergence lengths of the cross-sectional area, width, and depth, respectively, and the subscript 0 relates to the reference point near the estuary mouth.

A second assumption is that the flow width may be assumed to be constant in time while the lateral storage variation is described by the storage width ratio $r_{\mathrm{S}}=B_{\mathrm{S}} / \bar{B}$ where $B_{\mathrm{S}}$ is the storage width (Savenije et al., 2008). Finally, the instantaneous flow velocity $V$ of a moving particle is considered to consist of a steady component $U_{r}$, caused by the fresh water discharge, and a time-dependent component $U_{t}$, contributed by the tide:

$V=U_{t}-U_{r}, U_{t}=v \sin (\omega t), U_{r}=Q_{f} / \bar{A}$,

where $t$ is time, $Q_{f}$ is the river discharge (directed against the positive $x$ direction), $v$ is the tidal velocity amplitude, and $\omega$ is the tidal frequency.

It has been shown that the estuarine hydrodynamics of an arbitrary cross-section is controlled by a four dimensionless parameters that depend only on the local (i.e. fixed position) geometry and on the external forcing (Toffolon et al., 2006; Savenije et al., 2008; Toffolon and Savenije, 2011; Cai et al., 2012a, 2014). Table 1 presents these dimensionless parameters, including: $\zeta$ the dimensionless tidal amplitude, $\gamma$ the estuary shape number, $\chi$ the friction number, and $\varphi$ the dimensionless river discharge, where $\eta$ is the tidal amplitude, $c_{0}$ is the classical wave celerity of a frictionless progressive wave in a constant-width channel: 
$c_{0}=\sqrt{g \bar{h} / r_{\mathrm{S}}}$,

and $f$ is the dimensionless friction factor resulting from the envelope method (Savenije, 1998), defined as

$f=\frac{g}{K^{2} \bar{h}^{1 / 3}}\left[1-\left(\frac{4}{3} \zeta\right)^{2}\right]^{-1}$,

where $g$ is the acceleration due to gravity, $K$ is the ManningStrickler friction coefficient, the factor $4 / 3$ stems from a Taylor approximation of the exponent of the hydraulic radius in the friction term (it implies that $\zeta$ should be smaller than 3/4).

The dependent dimensionless variables are also shown in Table 1 , where $\delta$ is the damping number (a dimensionless description of the increase, $\delta>0$, or decrease, $\delta<0$, of the tidal wave amplitude along the estuary), $\mu$ the velocity number (the actual velocity amplitude scaled by the frictionless value in a prismatic channel), $\lambda$ the celerity number (the ratio between the theoretical frictionless celerity in a prismatic channel $c_{0}$ and the actual wave celerity $c$ ) and $\varepsilon$ the phase lag between high water (HW) and high-water slack (HWS) or between low water (LW) and low-water slack (LWS). For a simple harmonic wave $\varepsilon=\pi / 2-\left(\phi_{Z}-\phi_{U}\right)$, where $\phi_{Z}$ and $\phi_{U}$ are the phase of water level and velocity, respectively (Toffolon et al., 2006; Savenije et al., 2008).

Making use of the dimensionless parameters presented in Table 1, Cai et al. (2014) demonstrated that the analytical solutions for tidal dynamics in a local cross-section can be obtained by solving a set of four equations (see Table 2), i.e. the phase lag Eq. (T1), the scaling Eq. (T2), the celerity Eq. (T3), and the damping Eq. (T4), where

$\beta=\theta-r_{\mathrm{S}} \zeta \frac{\varphi}{\mu \lambda}, \theta=1-(\sqrt{1+\zeta}-1) \frac{\varphi}{\mu \lambda}$,

and $\Gamma_{\mathrm{H}}$ is a hybrid friction term that is obtained by a combination of the linearized and the nonlinear Lagrangian friction term, with the optimum weight of the linearized friction term $\Gamma_{L}$ being $1 / 3$, and $2 / 3$ of the nonlinear friction term $\Gamma$ :

$\Gamma_{\mathrm{H}}=\frac{2}{3} \Gamma+\frac{1}{3} \Gamma_{\mathrm{L}}$

with

$\Gamma= \begin{cases}\mu \lambda\left[1+\frac{8}{3} \zeta \frac{\varphi}{\mu \lambda}+\left(\frac{\varphi}{\mu \lambda}\right)^{2}\right] & \text { for } \varphi<\mu \lambda \\ \mu \lambda\left[\frac{4}{3} \zeta+2 \frac{\varphi}{\mu \lambda}+\frac{4}{3} \zeta\left(\frac{\varphi}{\mu \lambda}\right)^{2}\right] & \text { for } \varphi \geq \mu \lambda\end{cases}$

$\Gamma_{\mathrm{L}}=\frac{L_{1}}{2}-\zeta \frac{L_{0}}{3 \mu \lambda}$.

If $\varphi<1$, the expressions of coefficients $L_{0}$ and $L_{1}$ are given by (Dronkers, 1964, pp. 272-275)

$$
\begin{aligned}
& L_{0}=[2+\cos (2)]\left(2-\frac{4 \alpha}{\pi}\right)+\frac{6}{\pi} \sin (2 \alpha), \\
& L_{1}=\frac{6}{\pi} \sin (\alpha)+\frac{2}{3 \pi} \sin (3 \alpha)+\left(4-\frac{8 \alpha}{\pi}\right) \cos (\alpha),
\end{aligned}
$$

Table 1. Definition of dimensionless parameters.

\begin{tabular}{ll}
\hline \multicolumn{2}{c}{ Dimensionless parameters } \\
\hline Local variable & Dependent variable \\
\hline Tidal amplitude & Damping number \\
$\zeta=\eta / \bar{h}$ & $\delta=c_{0} \mathrm{~d} \eta /(\eta \omega \mathrm{d} x)$ \\
\hline Estuary shape & Velocity number \\
$\gamma=c_{0} /(\omega a)$ & $\mu=v /\left(r_{\mathrm{S}} \zeta c_{0}\right)=v \bar{h} /\left(r_{\mathrm{S}} \eta c_{0}\right)$ \\
\hline Friction number & Celerity number \\
$\chi=r_{\mathrm{S}} f c_{0} \zeta /(\omega \bar{h})$ & $\lambda=c_{0} / c$ \\
\hline River discharge & Phase lag \\
$\varphi=U_{r} / v$ & $\varepsilon=\pi / 2-\left(\phi_{Z}-\phi_{U}\right)$ \\
\hline
\end{tabular}

with

$\alpha=\arccos (-\varphi)$

If $\varphi \geq 1$, these coefficients become

$L_{0}=-2-4 \varphi^{2}, L_{1}=4 \varphi$

If the river discharge is negligible $\left(U_{r}=0\right)$, the damping Eq. (T4) (see Table 2) can be simplified as

$\delta=\frac{\mu^{2}}{1+\mu^{2}}\left(\gamma-\chi \mu \lambda \Gamma_{\mathrm{H}}\right)$,

with

$\Gamma_{\mathrm{H}}=\frac{2}{3} \mu \lambda+\frac{8}{9 \pi}$,

which corresponds to Eq. (27) of Cai et al. (2012a).

As an illustration, Fig. 1 shows the variation of the main dependent dimensionless parameters as a function of the shape number $\gamma$ and the dimensionless river discharge $\varphi$ for given values of $\zeta=0.1, \chi=2$ and $r_{\mathrm{S}}=1$, where the red lines represent the values in an ideal estuary (with no damping or amplification, i.e. $\delta=0, \lambda=1)$, of which the solutions are also presented in Table 2 .

\subsection{Iterative procedure to account for the residual water level}

Building on the work by Vignoli et al. (2003), Cai et al. (2014) proposed an analytical formula to calculate the residual water level:

$$
\begin{aligned}
& \bar{z}(x)=-\int_{0}^{x} \overline{\frac{V|V|}{K^{2} h^{4 / 3}}} \mathrm{~d} x, \overline{\frac{V|V|}{K^{2} h^{4 / 3}}} \\
& \approx \frac{1}{2}\left[\frac{V_{\mathrm{HW}}\left|V_{\mathrm{HW}}\right|}{K^{2}(\bar{h}+\eta)^{4 / 3}}+\frac{V_{\mathrm{LW}}\left|V_{\mathrm{LW}}\right|}{K^{2}(\bar{h}-\eta)^{4 / 3}}\right] \text {, }
\end{aligned}
$$


Table 2. Analytical solutions for tidal dynamics accounting for river discharge (Cai et al., 2014).

\begin{tabular}{lllll}
\hline Cases & Phase lag Eq. & Scaling Eq. & Celerity Eq. & Damping Eq. \\
\hline General & $\tan (\varepsilon)=\lambda /(\gamma-\delta)(\mathrm{T} 1)$ & $\mu=\sin (\varepsilon) / \lambda=\cos (\varepsilon) /(\gamma-\delta)(\mathrm{T} 2)$ & $\lambda^{2}=1-\delta(\gamma-\delta)(\mathrm{T} 3)$ & $\delta=\mu^{2}\left(\gamma \theta-\chi \mu \lambda \Gamma_{\mathrm{H}}\right) /\left(1+\mu^{2} \beta\right)(\mathrm{T} 4)$ \\
Ideal estuary & $\tan (\varepsilon)=1 / \gamma$ & $\mu=\sqrt{1 /\left(1+\gamma^{2}\right)}$ & $\lambda^{2}=1$ & $\delta=0$ \\
\hline
\end{tabular}
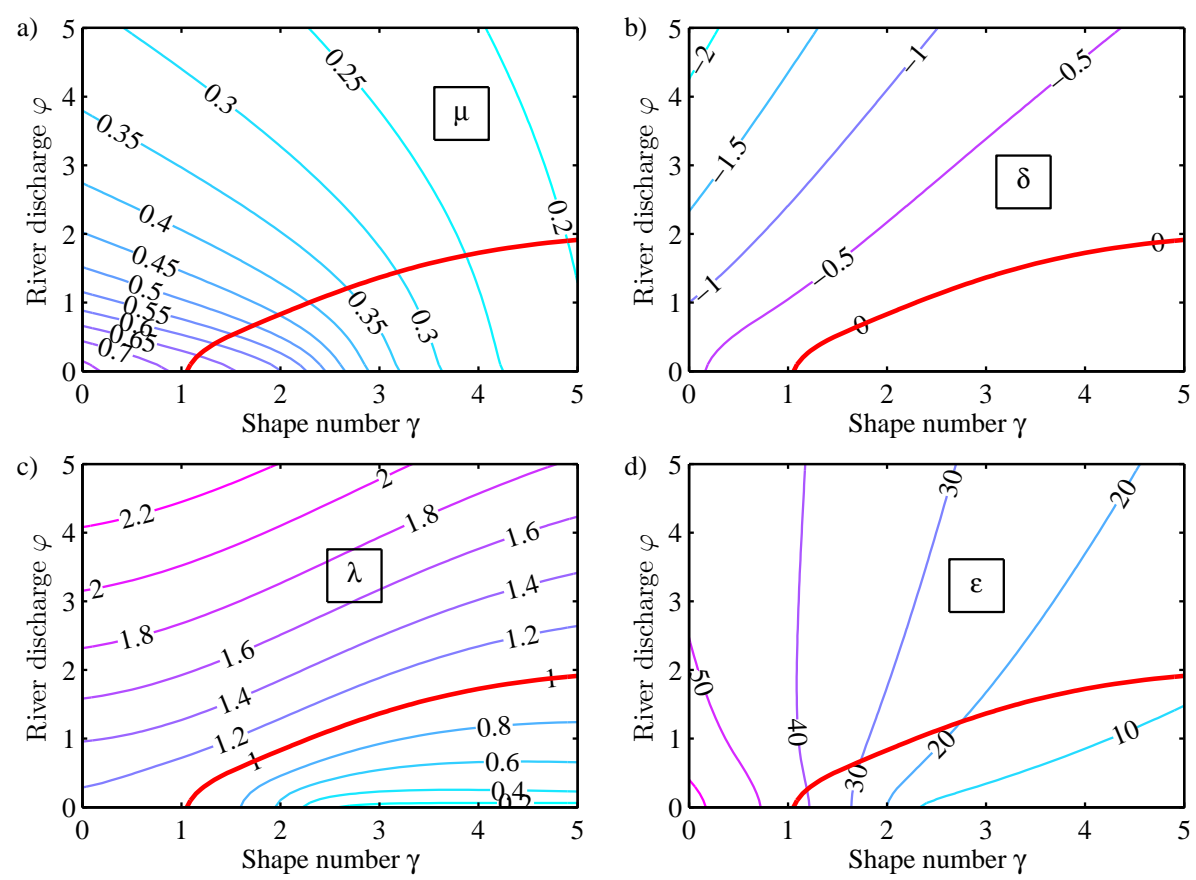

Figure 1. Contour plot of the main dependent parameters - (a) $\mu$, (b) $\delta$, (c) $\lambda$, (d) $\varepsilon-$ as a function of the estuary shape number $\gamma$ and the dimensionless river discharge term $\varphi$ obtained by solving Eqs. (T1)-(T4) (see Table 2) for given $\zeta=0.1, \chi=2$ and $r_{\mathrm{S}}=1$. The thick red lines represent the ideal estuary, where $\delta=0$ and $\lambda=1$.

where $V_{\mathrm{HW}}$ and $V_{\mathrm{LW}}$ are the instantaneous velocities at HW and LW:

$V_{\mathrm{HW}}=v \sin (\varepsilon)-U_{r}, V_{\mathrm{LW}}=-v \sin (\varepsilon)-U_{r}$.

It is important to recognize that Eq. (15) does not account for the effect of density difference between ocean and river water, which results in a residual water level slope amounting to $1.25 \%$ of the estuary depth over the salt intrusion length (see Savenije, 2005, P37). Since the resulted residual water level is relatively small compared with the tidally averaged depth and it is concentrated in the seaward part of an estuary, we neglect the density effect in this paper. Consequently, the tidally averaged depth including the residual water level is

$\overline{h_{\text {new }}}(x)=\bar{h}(x)+\bar{z}(x)$.

where $\bar{h}$ is the depth in relation to mean sea level.

The generic water levels in a tidal channel is illustrated in Fig. 2. For the case of negligible river discharge $\left(U_{r}=0\right)$, the residual water level is usually small compared with the depth relative to mean sea level, i.e. $\bar{z} \ll \bar{h}$. However, it becomes important and affects tidal damping in the upstream

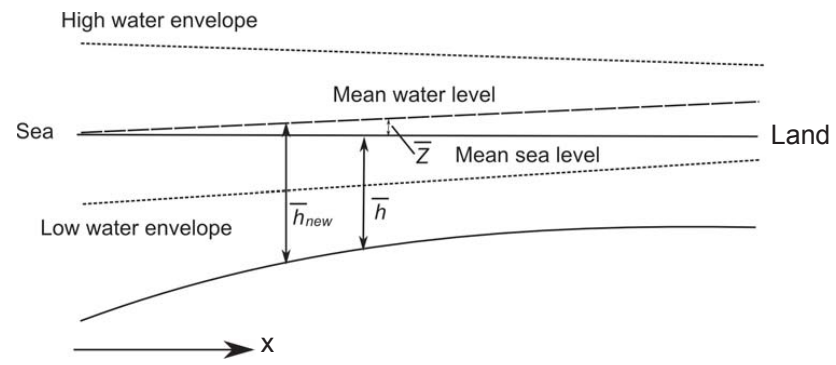

Figure 2. Sketch of the water levels in an estuary, where $\bar{z}$ is the residual water level.

part of an estuary where the influence of river discharge is considerable.

It should be noted that $\varphi$ is a local parameter because it depends on the velocity amplitude $v$ which is a function of $x$ (see Table 1). At the same time, the tidally averaged depth depends on the residual water level caused by the nonlinear friction term. Hence a fully explicit solution for the main dimensionless parameters (i.e. $\mu, \delta, \lambda, \varepsilon$ ) cannot be obtained. Therefore an iterative refinement is needed to obtain 


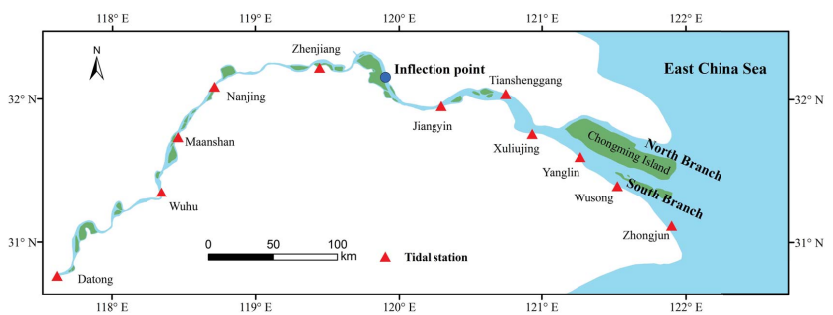

Figure 3. Sketch of the Yangtze estuary in China.

Table 3. Geometric characteristics in the Yangtze estuary.

\begin{tabular}{lrcrr}
\hline $\begin{array}{l}\text { Reach } \\
(\mathrm{km})\end{array}$ & $\begin{array}{r}\text { Depth } \bar{h} \\
(\mathrm{~m})\end{array}$ & $\begin{array}{r}\text { Convergence } \\
\text { length } a \\
(\mathrm{~km})\end{array}$ & $\begin{array}{r}\text { Convergence } \\
\text { length } b \\
(\mathrm{~km})\end{array}$ & $\begin{array}{r}\text { Convergence } \\
\text { length } d \\
(\mathrm{~km})\end{array}$ \\
\hline $0-275$ & 10.4 & 143 & 127 & -1135 \\
$275-580$ & 9.2 & 432 & 1349 & 636 \\
\hline
\end{tabular}

the correct wave behaviour. The following procedure usually converges in a few steps: (1) initially we assume $Q_{f}=0$ and calculate the initial values for the velocity number $\mu$, celerity number $\lambda$ and the tidal velocity amplitude $v$ (and hence dimensionless river discharge term $\varphi$ ) explicitly using the analytical solution proposed by Cai et al. (2012a); (2) taking into account the effect of river discharge $Q_{f}$, the revised damping number $\delta$, velocity number $\mu$, celerity number $\lambda$, velocity amplitude $v$ (and hence $\varphi$ ), and phase lag $\varepsilon$ are calculated by solving Eqs. (T4), (T2), (T3) and (T1) using a simple Newton-Raphson method; (3) subsequently we account for the residual water level according to Eq. (15); (4) this process is repeated until the result is stable, after which the dimensional parameters (e.g. $\eta, v$ ) are computed.

In order to follow along-channel variations of the estuarine sections, the iterative procedure is combined with a multireach approach (subdividing the whole estuary into short reaches), where the damping number $\delta$ is integrated in short reaches over which we assume the estuary shape number $\gamma$, the friction number $\chi$, and the dimensionless river discharge term $\varphi$ to be constant. This is done by using a simple explicit integration of the linear differential equation:

$\eta_{1}=\eta_{0}+\frac{\mathrm{d} \eta}{\mathrm{d} x} \Delta x=\eta_{0}+\frac{\delta \eta_{0} \omega \Delta x}{c_{0}}$,

where $\eta_{0}$ is the tidal amplitude at the downstream end of every short reach, while $\eta_{1}$ the tidal amplitude at a distance $\Delta x$ (e.g. $1 \mathrm{~km}$ ) upstream (an example of Matlab scripts are provided as Supplement).

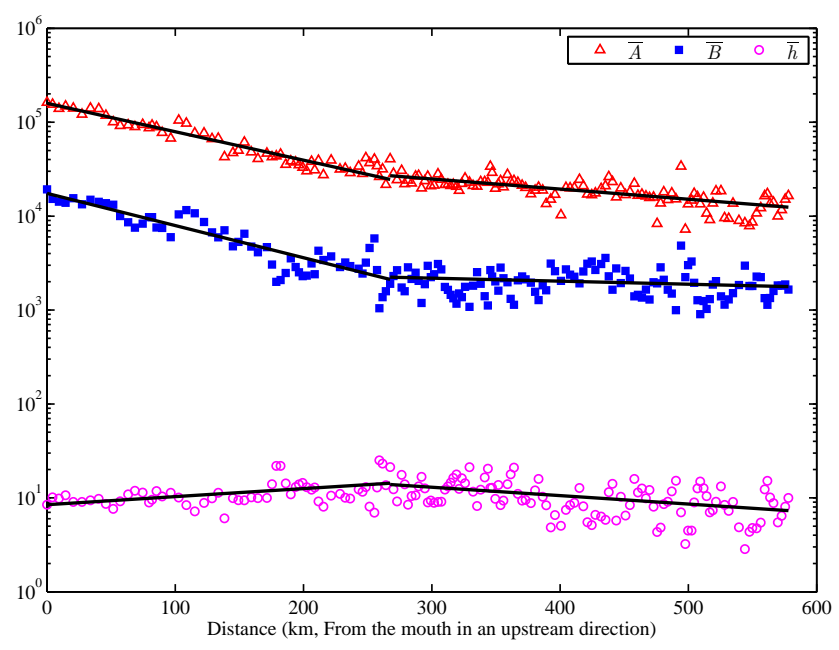

Figure 4. Semi-logarithmic plot of the tidally averaged crosssectional area $\bar{A}$ (triangles), width $\bar{B}$ (squares) and depth $\bar{h}$ (circles) in the Yangtze estuary. The drawn lines represent the fitted exponential curves.

\section{Application to the Yangtze estuary}

\subsection{Geometry of the Yangtze estuary}

The Yangtze River feeding the estuary is the largest river in China with an annual mean fresh water discharge of $28300 \mathrm{~m}^{3} \mathrm{~s}^{-1}$ measured at the upstream boundary of the estuary at Datong station (1950-2010). The tide penetrates from the mouth (Zhongjun station) up to Datong at a distance of approximately $630 \mathrm{~km}$ (see Fig. 3). The tidal near the estuary mouth is mesotidal with a mean tidal range of $2.7 \mathrm{~m}$ with the dominant tidal constituent being semi-diurnal. The main geometic parameters (i.e. cross-sectional area, width and depth) along the estuary axis are shown in Fig. 4, along with best-fitting lines based on Eq. (1). It can be seen that the whole estuary can be simplified as two reaches with the inflection point at $x=275 \mathrm{~km}$ (located between Jiangyin and Zhenjiang, see Fig. 3). The topographical parameters used to fit the geometry are presented in Table 3 . We see that both the cross-sectional area and width exponentially decrease in landward direction from the estuary mouth, while there is a slight increase of the averaged depth in the seaward reach $(x=0-275 \mathrm{~km})$. From $275 \mathrm{~km}$ upstream the depth gradually reduces. It is noted that the Yangtze estuary is a branched system, where the seaward part is divided by the Chongming Island into the North Branch and the South Branch. In this paper, we only focus on the South Branch and the upper reach, since the North Branch is much smaller compared to the South Branch, and functions in isolation (Zhang et al., 2012b). 

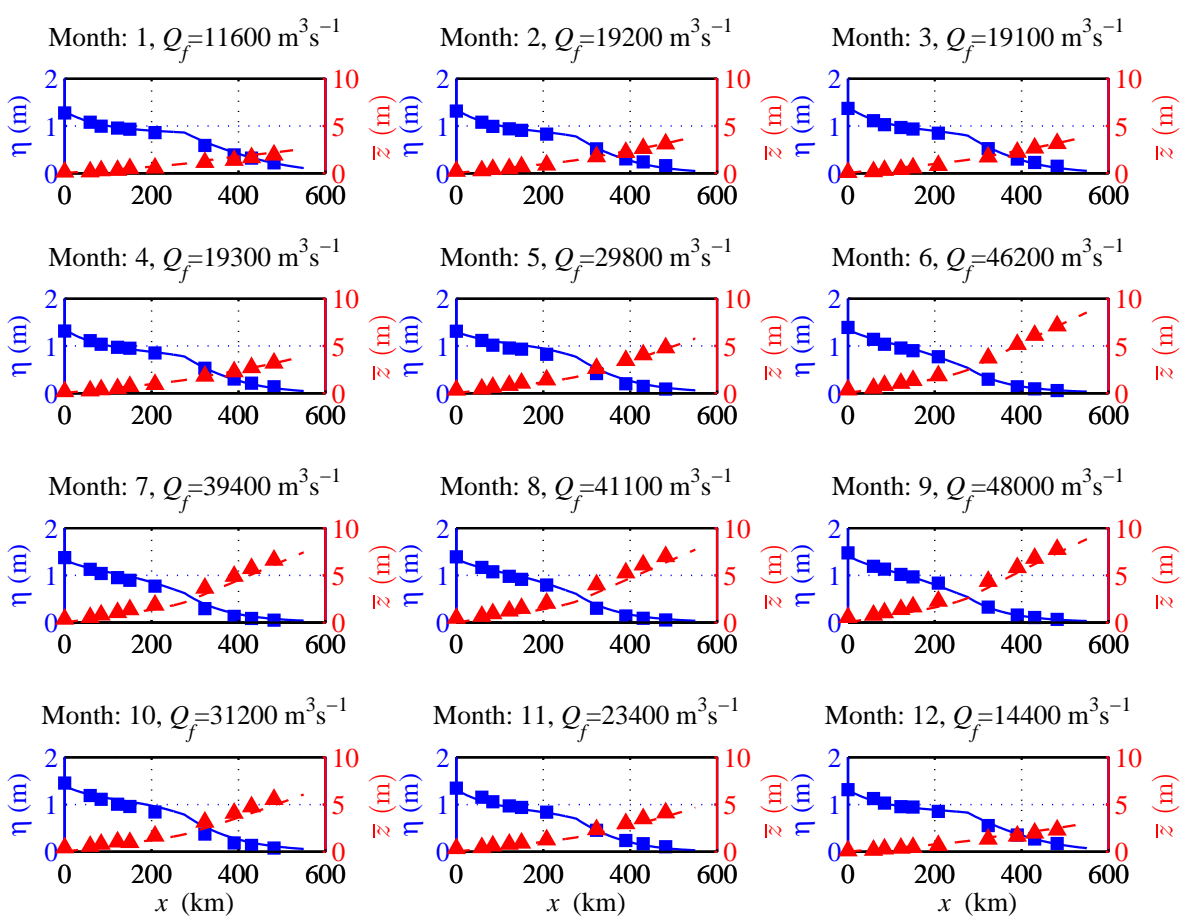

Figure 5. Comparison between analytically computed monthly averaged values (left-hand vertical scale: tidal amplitude; right-hand vertical scale: residual water level) and observations in the Yangtze estuary in 2005.

\subsection{Calibration and verification of the model}

The analytical model presented in Sect. 2 was calibrated and verified with the monthly averaged tidal amplitudes and water levels collected in 2005. It is important to point out that the model uses a variable depth in order to account for along-channel variations of the estuarine sections. Figure 5 shows the comparison between the measurements and the analytically computed tidal amplitude and tidally averaged depth along the estuary in 2005. We see that the correspondence with the observed values in each month is good, which suggests that the proposed analytical model can well reproduce the tidal dynamics with a wide range of river discharge $\left(11600-48000 \mathrm{~m}^{3} \mathrm{~s}^{-1}\right)$. The calibrated Manning-Strickler friction coefficient $K$ and storage width ratio $r_{\mathrm{S}}$ are presented in Table 4. A relatively larger $K$ value in the seaward reach of 70 and $60 \mathrm{~m}^{1 / 3} \mathrm{~s}^{-1}$ in the landward reach has been used to calibrate the model, which is reasonable since the downstream part has a higher mud content, distinguishing between riverine and marine dominated parts of the estuary. It is interesting to note that the calibrated $r_{\mathrm{S}}$ in the dry season (months 1, 2, 3, 4, 11 and 12) is larger than that in the wet season (months 5, 6, 7, 8, 9 and 10), which is possibly due to the fact that the influence of storage area (such as marshes and tidal flats) is much stronger in the dry season compared with that in the wet season. A possible explanation for this phenomenon is discussed in Sect. 3.3. Figure 5 also shows the resulted residual water level due to nonlinear
Table 4. Calibrated parameters used in the analytical model.

\begin{tabular}{cccc}
\hline \multirow{2}{*}{$\begin{array}{c}\text { Reach } \\
(\mathrm{km})\end{array}$} & $\begin{array}{c}\text { Manning-Strickler } \\
\text { friction } K \\
\left(\mathrm{~m}^{1 / 3} \mathrm{~s}^{-1}\right)\end{array}$ & \multicolumn{2}{c}{ Storage width ratio $r_{\mathrm{S}}$} \\
\cline { 3 - 4 } & & $\begin{array}{c}\text { Dry season } \\
(1,2,3,4,11,12)\end{array}$ & $\begin{array}{c}\text { Wet season } \\
(5,6,7,8,9,10)\end{array}$ \\
\hline $0-275$ & 70 & 1.4 & 1 \\
$275-580$ & 60 & 1.8 & 1 \\
\hline
\end{tabular}

friction according to Eq. (15) (i.e. including bottom friction and river discharge). It can be seen that the residual water level is increased with river discharge, which indicates that the residual effect is more important in the wet season.

According to Eq. (2) the flow velocity consists of two components: the tidal component with velocity amplitude $v$ and the velocity of the river discharge $U_{r}$. In Fig. 6 the two components and the ratio between them (i.e. $\varphi$ defined in Table 1) are presented for the Yangtze estuary in 2005. A critical point can be defined where the river flow velocity is equal to the velocity amplitude (i.e. $\varphi=1$ ), upstream of which the influence of river discharge is dominant over the tidal flow. We can see from Fig. 6 that the location of this point varies with river discharge. At a small discharge of $11600 \mathrm{~m}^{3} \mathrm{~s}^{-1}$ in January, the velocity of the river discharge becomes dominant from $368 \mathrm{~km}$ onward, while with a large river discharge of $48000 \mathrm{~m}^{3} \mathrm{~s}^{-1}$ in September this occurs at $x=139 \mathrm{~km}$. 

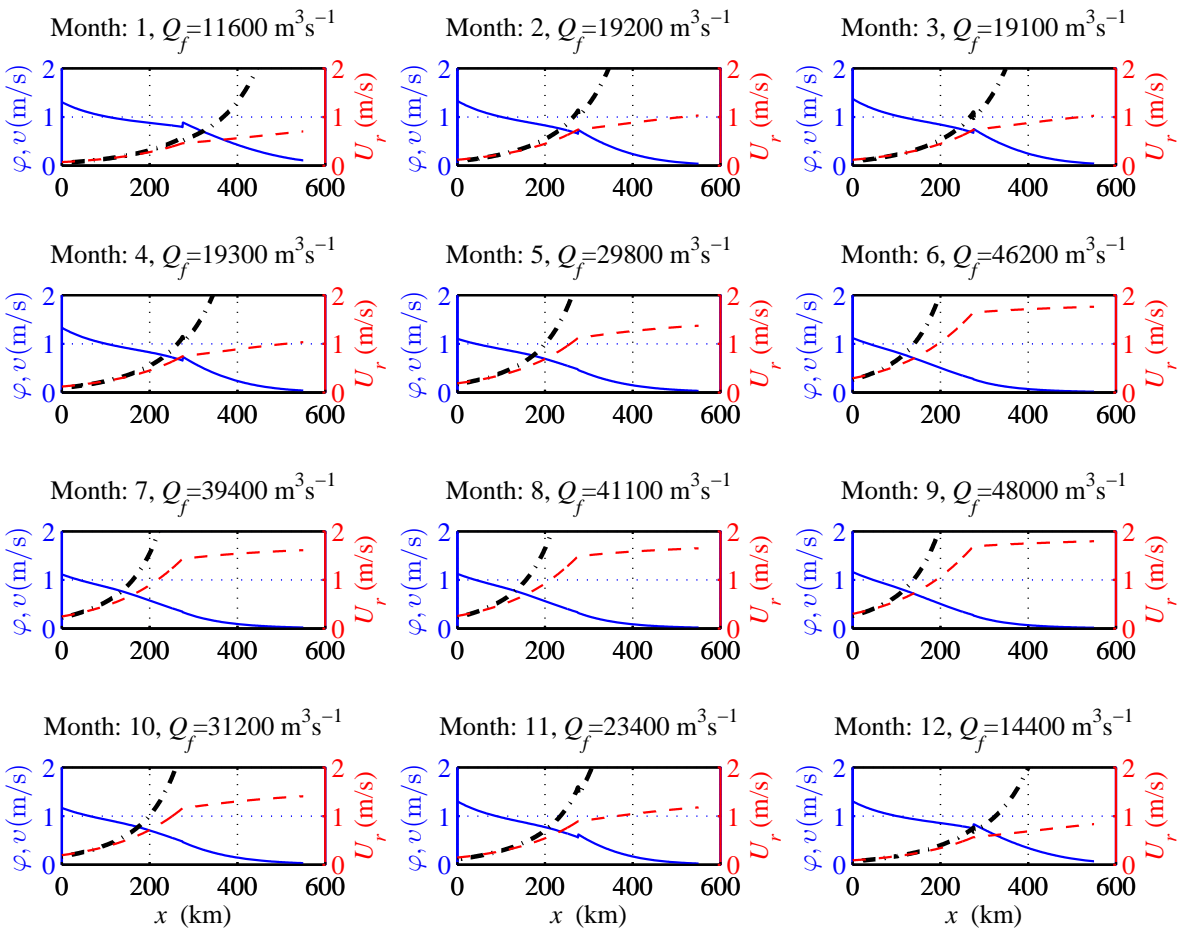

Figure 6. Longitudinal variation of the tidal velocity amplitude $v$ and river flow velocity $U_{r}$ along the Yangtze estuary in 2005 . The dashdotted line represents the ratio of the river flow velocity to the tidal velocity amplitude (i.e. the dimensionless river discharge term $\varphi$ ).

It is worth examining the tidal wave propagation in convergent estuaries with significant river discharge. We focus on analytical solutions for infinite length estuaries (long coastal plain estuaries), where there is no reflected wave (see also Jay, 1991). In this case, the value of the phase lag $\varepsilon$ is always between 0 and $\pi / 2$ (i.e. mixed wave, see Savenije, 2005, 2012). If $\varepsilon=\pi / 2$, the tidal wave is a progressive wave, which corresponds to a frictionless wave in a prismatic channel. If $\varepsilon=0$, the tidal wave is an "apparently standing" wave (the wave is not formally a standing wave generated by the superimposition of incident and reflected waves; rather it is an incident wave that mimics a standing wave with a phase difference of $90^{\circ}$ between water level and velocity and a wave celerity tending to infinity).

Figure 7 shows the variation of the wave celerity $c$ and phase lag $\varepsilon$ along the Yangtze estuary under different river discharge conditions. We see that the wave celerity $c$ is smaller than the classical wave celerity $c_{0}$, which is mainly due to the fact that the Yangtze estuary is a damped estuary under significant influence of river discharge. As expected, we see that the classical wave celerity during the wet season is larger than that during the dry season, due to the larger residual water level and smaller storage width ratio (according to Eq. 3). However, we see that the increase of the actual wave celerity is not significant, which is due to the counteraction of the tidal damping by river discharge (see the celerity Eq. T3 in Table 2). With regard to the variation of the phase lag, the values are in the range of $50-70^{\circ}$, which suggests that the tidal character is close to a progressive wave $\left(\varepsilon=90^{\circ}\right)$. Meanwhile, it can be seen that the bigger the river discharge the smaller the phase lag.

\subsection{Effect of river discharge on tidal dynamics}

With the analytical model presented in Sect. 2, the major mechanisms of how river discharge affects tidal dynamics can be identified. One mechanism is increasing friction, which can be seen from the damping Eq. (T4). The influence of river discharge on tidal dynamics is very similar to that of the friction number $\chi$. This can be demonstrated by rewriting the friction parameter $\Gamma_{\mathrm{H}}$ in Eq. (6):

$$
\Gamma_{\mathrm{H}}= \begin{cases}\frac{2}{3} \mu \lambda\left[1+\frac{8}{3} \zeta \frac{\varphi}{\mu \lambda}+\left(\frac{\varphi}{\mu \lambda}\right)^{2}\right]+\frac{1}{3}\left(\frac{L_{1}}{2}-\zeta \frac{L_{0}}{3 \mu \lambda}\right) & \\ =\frac{2}{3} \mu \lambda\left[1+\frac{8}{3} \zeta \frac{\varphi}{\mu \lambda}+\left(\frac{\varphi}{\mu \lambda}\right)^{2}\right]+\frac{8}{9 \pi}\left(\frac{3 \pi}{16} L_{1}-\frac{\pi}{8} \frac{L_{0} \zeta}{\mu \lambda}\right) & \text { for } \varphi<\mu \lambda \\ \frac{2}{3} \mu \lambda\left[\frac{4}{3} \zeta+2 \frac{\varphi}{\mu \lambda}+\frac{4}{3} \zeta\left(\frac{\varphi}{\mu \lambda}\right)^{2}\right]+\frac{1}{3}\left(\frac{L_{1}}{2}-\zeta \frac{L_{0}}{3 \mu \lambda}\right) & \\ =\frac{2}{3} \mu \lambda\left[\frac{4}{3} \zeta+2 \frac{\varphi}{\mu \lambda}+\frac{4}{3} \zeta\left(\frac{\varphi}{\mu \lambda}\right)^{2}\right]+\frac{8}{9 \pi}\left(\frac{3 \pi}{16} L_{1}-\frac{\pi}{8} \frac{L_{0} \zeta}{\mu \lambda}\right) & \text { for } \varphi \geq \mu \lambda,\end{cases}
$$

where we see that the influence of river discharge is basically that of increasing friction by a factor depending on the dimensionless river discharge $\varphi$ (i.e. by comparing the last two terms in Eq. (19) with the right-hand side of Eq. (14), see more details in Appendix A).

The second mechanism is related to the residual water level caused by the nonlinear frictional effect according to 

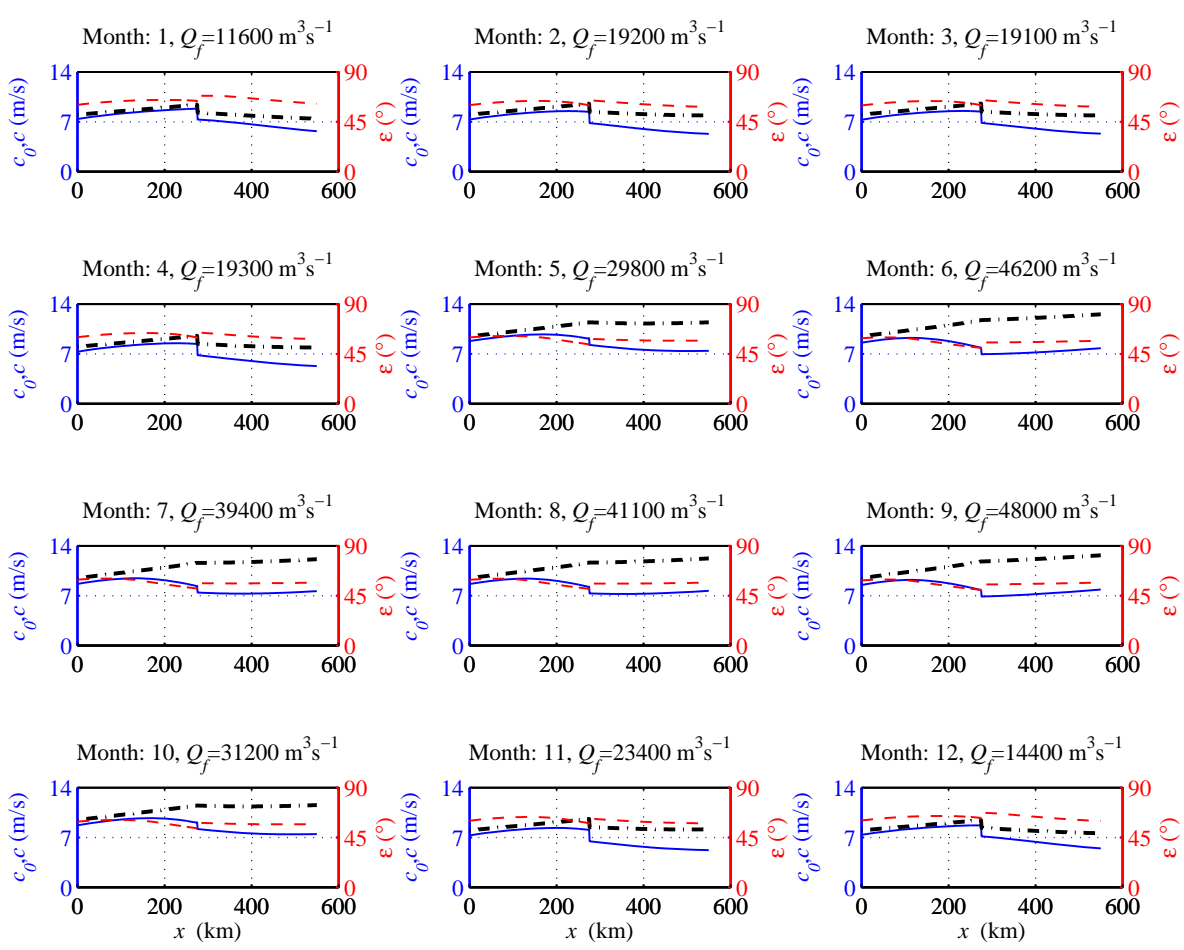

Figure 7. Longitudinal variation of the wave celerity $c$ (blue) and the phase lag $\varepsilon$ (red) along the Yangtze estuary in 2005. The dash-dotted line represents the classical wave celerity $c_{0}$ from Eq. (3).

Eq. (15), in which the river discharge plays an important role. We should recognize that this residual effect (indicating higher depth) partly acts the other way around, i.e. reducing the tidal damping, since it reduces the bottom friction (smaller $\chi$ ) in Eq. (T4). Additionally, the residual water level induces a slight increase of the cross-sectional area convergence (a smaller $\gamma$ ), especially in the upstream part of the estuary with large depth divergence, since $1 / a=1 / b-1 /|d|$, where the depth convergence length $d$ is negative.

The third mechanism is linked to the storage area, which is represented by the storage width ratio $r_{\mathrm{S}}$. As a result of the calibration in the Yangtze estuary (see Sect. 3.1), we note that the effect of the storage area on the tidal dynamics is stronger in the dry season (bigger $r_{\mathrm{S}}$ ), which indicates more friction (larger $\chi$ ) and lower channel convergence (smaller $\gamma$ ) compared with those in the wet season. This seasonal variation of the storage width ratio is illustrated in Fig. 8. In the case of low river discharge, the channel width changes more strongly than the depth, resulting in a dominant lateral flow between the storage area and the main channel over the tidal cycle. Conversely, the depth increases more substantially compared with the width in the case of high river discharge, leading to a more dominant longitudinal flow in the storage area. As a result, the flow in the storage area is in the same direction as that in the main channel, which suggests a smaller storage width ratio for high river discharge condition.
To provide insights into the relative importance of these three mechanisms, we applied the analytical model under different river discharge conditions (varying between 5000 and $60000 \mathrm{~m}^{3} \mathrm{~s}^{-1}$ ). A yearly averaged tidal amplitude of $1.36 \mathrm{~m}$ at Zhongjun station (2005) is imposed at the seaward boundary. The calibrated parameters (including the friction coefficient $K$ and storage width ratio $r_{\mathrm{S}}$ ) are fixed for the sensitivity experiments. For simplicity, we adopted the calibrated $r_{\mathrm{S}}$ in the dry season when the river discharge is below $25000 \mathrm{~m}^{3} \mathrm{~s}^{-1}$, while using the $r_{\mathrm{S}}$ in the wet season for river discharge larger than $25000 \mathrm{~m}^{3} \mathrm{~s}^{-1}$. In Fig. 9 we see that both the residual water level $\bar{z}$ and the parameter $\Gamma_{\mathrm{H}}$ are increased with river discharge, which counteract each other, leading to changes in the friction term $\chi \mu \lambda \Gamma_{\mathrm{H}}$ in the damping Eq. (T4), the friction number $\chi$ and the shape number $\gamma$. As the river discharge increases, we see from Fig. $9 \mathrm{c}$ that the friction number $\chi$ is decreased, which indicates a reduction of the bottom friction. However, it is noted that the whole friction term $\chi \mu \lambda \Gamma_{\mathrm{H}}$ is increased with river discharge (see Fig. 9d), which suggests that the increased friction due to river discharge $\left(\Gamma_{\mathrm{H}}\right)$ is dominant over the reduced friction due to residual water level. On the other hand, the estuary shape number $\gamma$ is decreased with river discharge for cases using the same $r_{\mathrm{S}}$, which is due to an increase of the residual water level. The lower values of $\gamma$ for small river discharge $\left(Q_{f}<25000 \mathrm{~m}^{3} \mathrm{~s}^{-1}\right)$ in the seaward reach is mainly caused by the adoption of larger storage width ratio, since the depth 


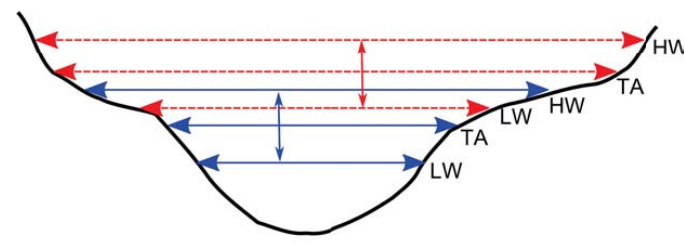

(a) Cross-section
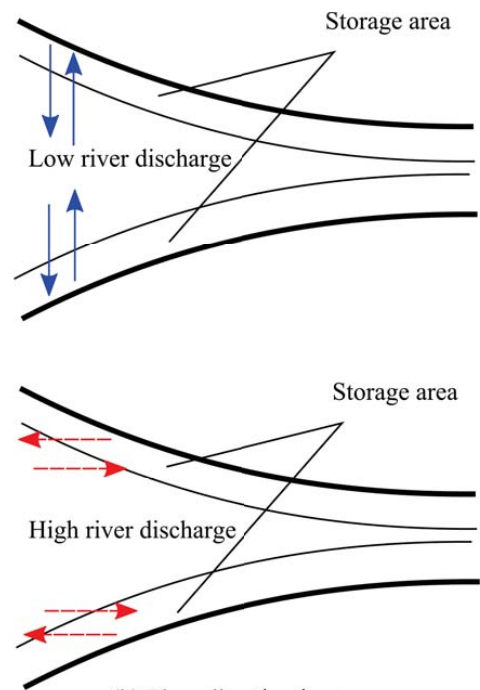

(b) Flow direction in storage area

Figure 8. Variation of the water levels (LW: low water level, TA: tidally averaged water level, HW: high water level) in a cross-section (a) and the dominated flow direction in the storage area (b). The blue drawn line represents the case with low river discharge, while the red dashed line represents the case with high river discharge.
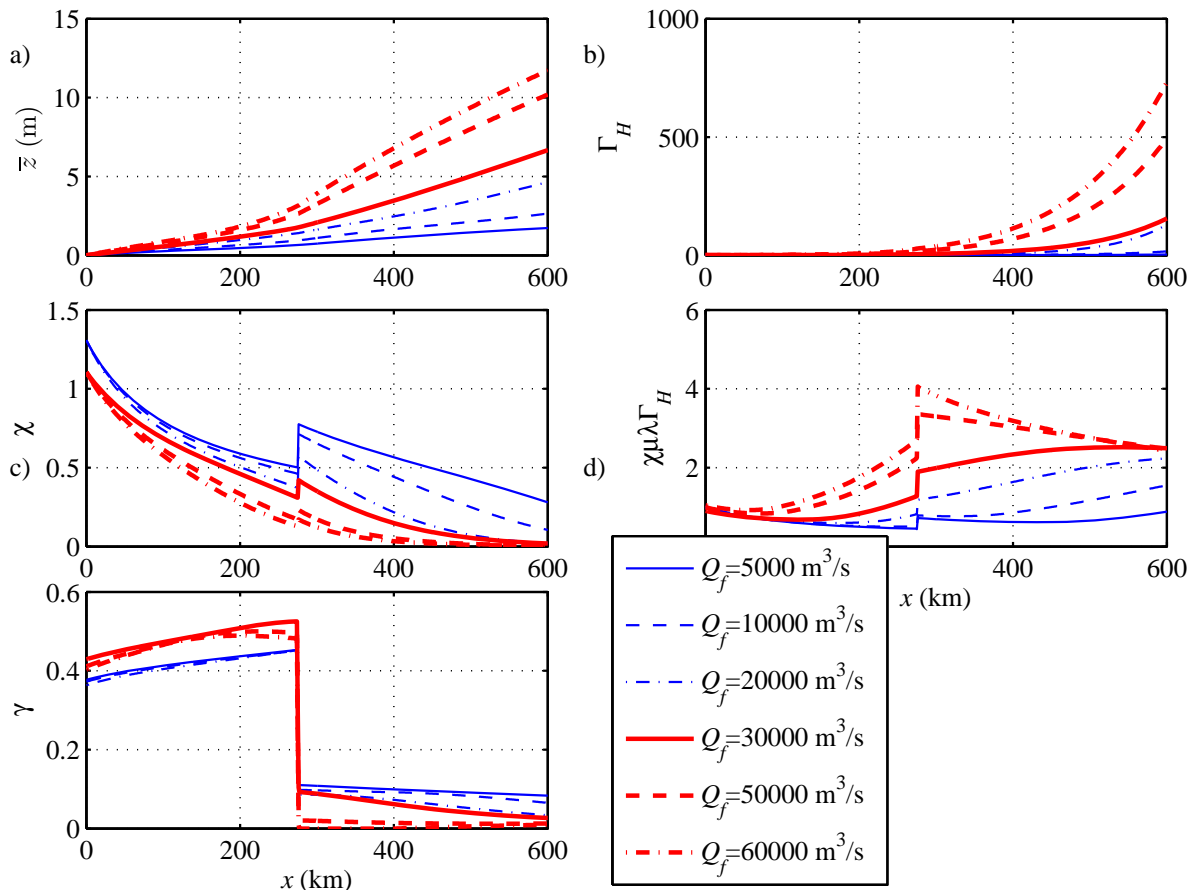

Figure 9. Longitudinal variation of the residual water level $\bar{z}(\mathbf{a})$, the parameter $\Gamma_{\mathrm{H}}(\mathbf{b})$, the friction number $\chi(\mathbf{c})$, the friction term $\chi \mu \lambda \Gamma_{\mathrm{H}}$ in Eq. (T4), and the shape number $\gamma$ (e) in the Yangtze estuary under different river discharge conditions.

divergence is rather small. Conversely, in the upstream reach, where the depth divergence is remarkable, we see a smaller $\gamma$ for larger river discharge conditions.

The effect of river discharge on the main features of the tidal dynamics is shown in Fig. 10. We see that the tidal amplitude, velocity amplitude and phase lag are reduced with river discharge, especially in the upper reach of the estuary, where it gradually becomes more riverine in character (indicating larger river flow velocity, see Fig. 10c). The abrupt higher tidal amplitude observed near the estuary mouth (see Fig. 10a) for the cases of larger river discharge $\left(Q_{f}>25000 \mathrm{~m}^{3} \mathrm{~s}^{-1}\right)$ is due to the assumption that the adopted storage width ratio is smaller in the wet season than in the dry season (see Table 2). With regard to the wave 

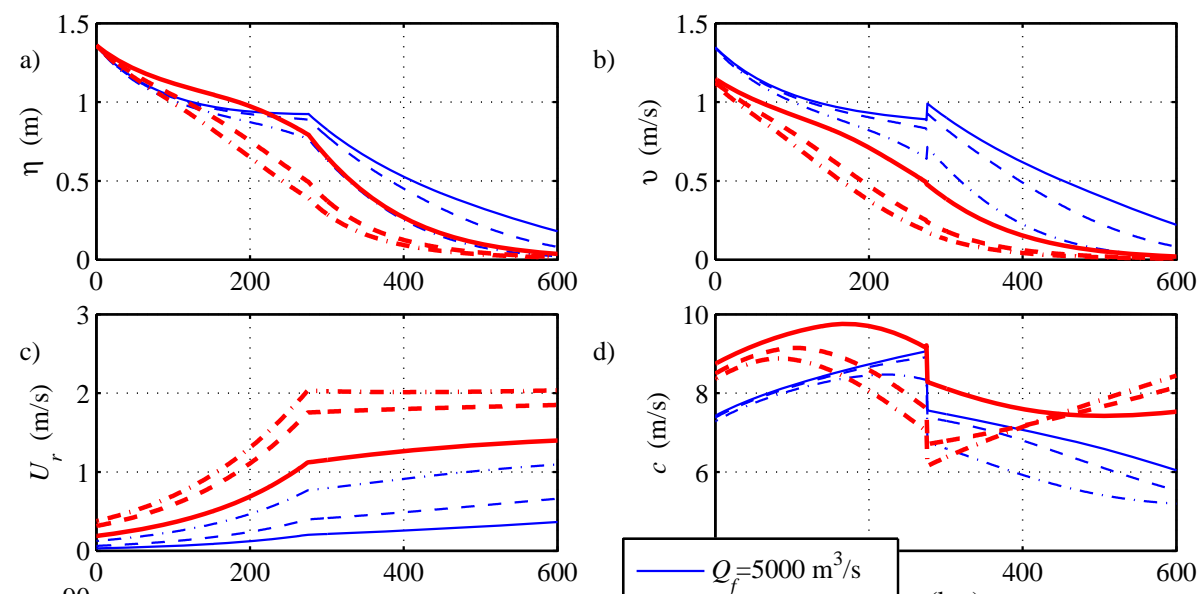

d)

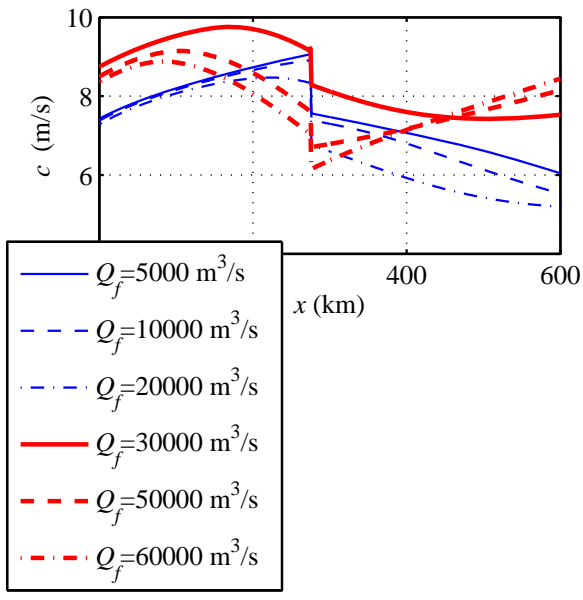

Figure 10. Longitudinal variation of the tidal amplitude $\eta(\mathbf{a})$, the velocity amplitude $v$ (b), the river flow velocity $U_{r}$ (c), the wave celerity $c$ (d), and the phase lag $\varepsilon(\mathbf{e})$ in the Yangtze estuary under different river discharge conditions.

celerity, it tends to increase with river discharge although there is significant damping caused by river discharge. The reason is mainly due to the increase of residual water level when increasing the river discharge.

\subsection{A new approach for estimating fresh water discharge}

Reliable estimation of fresh water discharge into estuaries is a critical component of water resources management (e.g. salt intrusion, freshwater withdrawal, flood protection), yet fresh water discharge into estuaries remains poorly observed, as it requires observations during a full tidal cycle. The analytical model for tidal wave propagation makes clear that tide and river discharge interact and are governed by the damping Eq. (T4) in Table 2. As a result, it is possible to develop an analytical equation to determine river discharge based on measurements of tidal water levels. If the tidal damping $\delta$ and the tidally averaged depth (including residual water level) $\bar{h}$ are known, we are able to use the inverse analytical model to predict the fresh water discharge. Moftakhari et al. (2013) also proposed a method to predict the fresh water discharge based on analysis of tidal statistics, using known astronomical forcing. However, they did not recognize the importance of residual water level. As opposed to the regression model they used for fresh water discharge estimation, the method presented here is fully analytical and takes into account both the friction and residual water level.
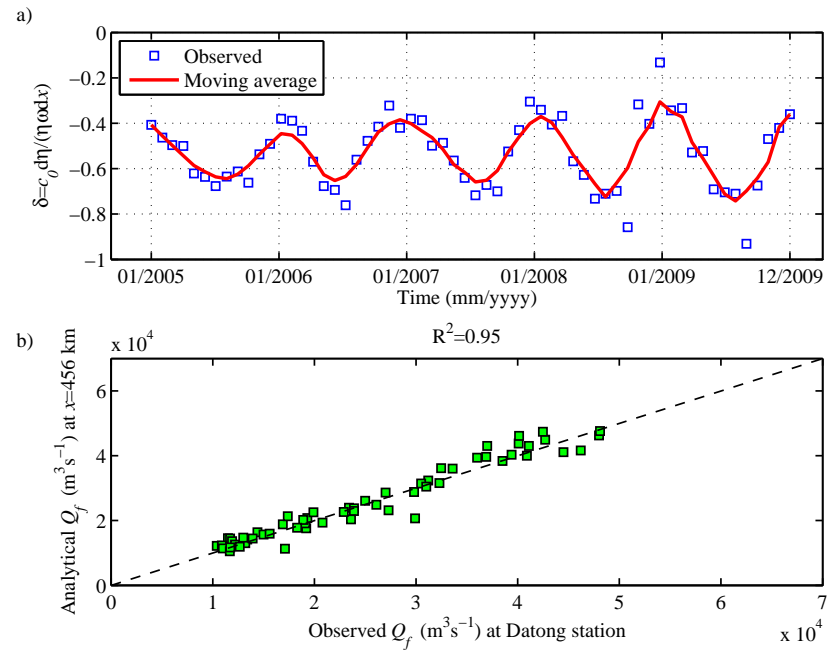

Figure 11. (a) Comparison between observed tidal damping $\delta$ and its corresponding moving average value with a window of 5 months; (b) comparison between analytically predicted fresh water discharge and observations (at Datong tidal station) in the Yangtze estuary in different months of 2005-2009. $R^{2}$ is the coefficient of determination.

Knowing $\delta$ and $\gamma$, the tidal variables $\varepsilon, \lambda$ and $\mu$ can be determined using Eqs. (T1), (T3) and (T2). Subsequently the damping Eq. (T4) in the upstream river discharge-dominated zone $(\varphi \geq \mu \lambda)$ is used to predict the fresh water discharge. Recalling that $L_{0}=-2-4 \varphi^{2}, L_{1}=4 \varphi$ for the case of $\varphi \geq 1$ 
and rearranging Eq. (T4), it is possible to obtain a quadratic equation of $\varphi$ :

$\alpha_{1} \varphi^{2}+\alpha_{2} \varphi+\alpha_{3}=0$,

with

$$
\begin{aligned}
\alpha_{1} & =-4 \chi_{0} \mu^{2} \zeta^{2} /\left[3-16 \zeta^{2} / 3\right], \\
\alpha_{2} & =r_{\mathrm{S}} \delta \mu \zeta / \lambda-2 \mu^{3} \chi_{0} \lambda \zeta /\left[1-(4 \zeta / 3)^{2}\right] \\
& -(\mu \gamma-\delta \mu)(\sqrt{1+\zeta}-1) / \lambda, \\
\alpha_{3} & =-\chi_{0} \mu^{2} \zeta^{2}\left(8 \mu^{2} \lambda^{2} / 9+2 / 9\right) /\left[1-(4 \zeta / 3)^{2}\right] \\
& -\delta+\mu^{2} \gamma-\delta \mu^{2},
\end{aligned}
$$

where $\chi_{0}$ is the reference friction number, defined as

$\chi_{0}=\chi\left[1-(4 \zeta / 3)^{2}\right] / \zeta=r_{\mathrm{S}} g c_{0} /\left(K^{2} \omega \bar{h}^{4 / 3}\right)$,

where the $r_{\mathrm{S}}$ and $K$ are the calibrated parameters.

It can be seen from Eqs. (21) and (22) that both $\alpha_{1}$ and $\alpha_{2}$ are always negative for given $\zeta<0.75$. Thus, for given values of $\delta$ (always negative), $\gamma, \lambda, \mu, \chi_{0}$ and $\zeta$, the positive solution is

$\varphi=\frac{-\alpha_{2}-\sqrt{\alpha_{2}^{2}-4 \alpha_{1} \alpha_{3}}}{2 \alpha_{1}}$.

With this solution for $\varphi$, an explicit solution can be obtained for $Q_{f}$ :

$Q_{f}=\bar{A} U_{r}=\bar{A} \varphi v$.

In fact, the introduced damping equation (i.e. Eq. T4 in Table 2) can be regarded as a modified Stage-Discharge relationship that accounts for the effects of residual water level slope (i.e. $\mathrm{d} \bar{h} / \mathrm{d} x$ ) and tidal damping (i.e. $\mathrm{d} \eta / \mathrm{d} x$ ), while the resulted predictive Eq. (25) is a modified Manning equation that is applicable to estuaries. A detailed derivation can be found in Appendix B.

To reduce the statistical uncertainties in estimating tidal damping $\delta=\frac{1}{\eta} \frac{\mathrm{d} \eta}{\mathrm{d} x} \frac{c_{0}}{\omega}$ (which is rather sensitive to changes in observed tidal amplitudes), we propose to use a moving average filter to smooth the estimated tidal damping. As an example, Fig. 11a shows the estimated tidal damping $\delta$ between 2005 and 2009 at $x=456 \mathrm{~km}$ in the Yangtze estuary located between the two points where tidal observations can be obtained (i.e. Wuhu and Maanshan tidal stations, see Fig. 3) and its corresponding moving average value with a window of 5 months. The obtained $\delta$ is subsequently used to predict the monthly averaged fresh water discharge $Q_{f}$ from Eq. (26). In this case we used the calibrated Manning-Strickler friction coefficient $K=60 \mathrm{~m}^{1 / 3} \mathrm{~s}^{-1}$ and the calibrated storage

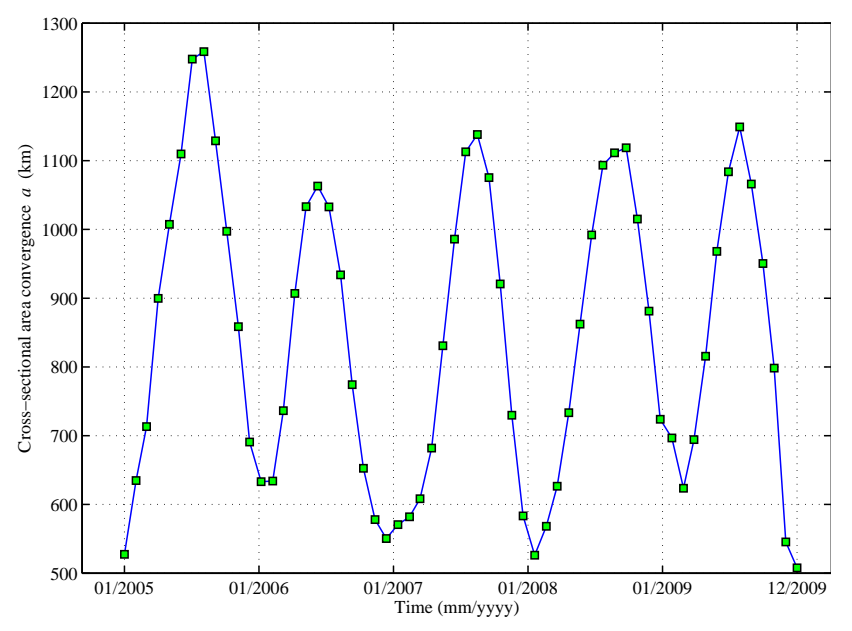

Figure 12. Seasonal variation of the cross-sectional area convergence $a$ due to the changes in residual water level slope $\mathrm{d} \bar{h} / \mathrm{d} x$ at $x=456 \mathrm{~km}$ in the Yangtze estuary.

width ratio of $r_{\mathrm{S}}=1.5$. We see from Fig. $11 \mathrm{~b}$ that the correspondence with observations is good $\left(R^{2}=0.95\right)$, which suggests that the proposed analytical model can be a useful tool to have a first-order estimation of fresh water discharge in the tidal region. The deviation from observations is probably related to the simplification of a rectangular cross-section and observational error.

It is important to note that even if the Manning-Strickler coefficient $K$ and the storage width ratio $r_{\mathrm{S}}$ can not be calibrated due to the lack of observed fresh water discharge data, it is still possible to apply the proposed analytical approach. This is made possible by calibrating the analytical model for tidal wave propagation against the observed tidal amplitude in the seaward part of the estuary, where the influence of river discharge on tidal damping is negligible. Assuming that $K$ and $r_{\mathrm{S}}$ in the upstream part are the same as that in the seaward part, the analytical approach presented in this section can be used to hindcast fresh water discharge based on the tidal water level observations.

We also note that the cross-sectional area convergence $a$ is no longer a constant at the studied position $(x=456 \mathrm{~km})$ due to the significant variation of the residual water level slope $\mathrm{d} \bar{h} / \mathrm{d} x$, which is implicitly included in the parameter of $a$ since $\frac{1}{a}=\frac{1}{b}+\frac{1}{d}=-\frac{1}{\bar{B}} \frac{\mathrm{d} \bar{B}}{\mathrm{~d} x}-\frac{1}{\bar{h}} \mathrm{~d} \overline{\mathrm{h}} \mathrm{d}$. The seasonal variation of $a$ is given in Fig. 12, where we see a larger value of $a$ during wet season while a smaller value during dry season.

Figure 13 shows the analytically predicted fresh water discharge for a range of tidally averaged depth $\bar{h}$ (9 to $20 \mathrm{~m}$ ) and damping number $\delta$ ( -2 to 0 ) according to Eq. (26) (the Matlab scripts are provided as Supplement). For simplicity, we assumed a fixed tidal amplitude at $x=456 \mathrm{~km}$ equal to the monthly averaged value of $0.14 \mathrm{~m}$. It can be seen from Fig. 13 that the fresh water discharge is mainly determined by two controlling factors. Both the tidally averaged depth 


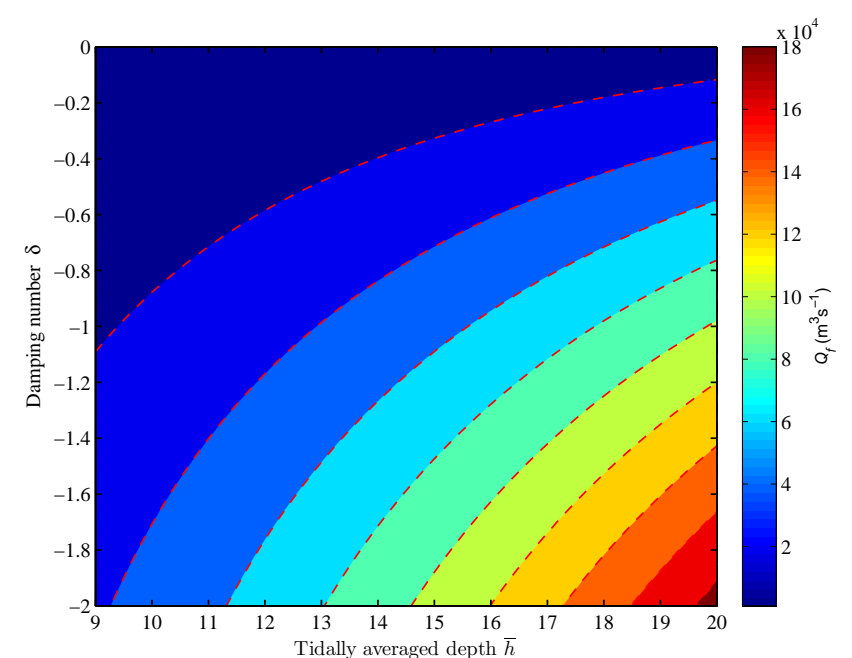

Figure 13. Contour plot of the predicted fresh water discharge at $x=456 \mathrm{~km}$ as a function of the tidally averaged depth $\bar{h}$ and the damping number $\delta$ for given tidal amplitude $\eta=0.14 \mathrm{~m}$, convergence length $a=432 \mathrm{~km}$, Manning-Strickler friction coefficient $K=60 \mathrm{~m}^{1 / 3} \mathrm{~s}^{-1}$ and storage width ratio $r_{\mathrm{S}}=1.5$.

and the tidal damping tend to result in a larger fresh water discharge.

Further work will be required to test the accuracy of the explicit Eq. (26) with more detailed measurements (e.g. daily river discharge and water level).

\section{Conclusions}

An analytical model has been applied to the Yangtze estuary where the influence of river discharge is significant. The method involves solving a set of four implicit equations (i.e. the phase lag, the scaling, the celerity and the damping equations), in combination with an iterative procedure to account for the influence of residual water level due to nonlinear frictional effect. The results show a good agreement with observed tidal amplitude and water level in both dry and wet seasons, which suggest that the presented analytical model can be a powerful instrument for assessing the influence of human interventions (e.g. dredging, freshwater withdrawal) on tidal dynamics.
The effect of river discharge on tidal damping is not trivial, triggering different effects that partly counteract each other. We show that the river discharge affects tidal damping primarily through the friction term, and subsequently by the residual water level and the storage area, whereby the friction term and the storage area tend to increase the tidal damping, while the residual water level affects the tidal damping by reducing the bottom friction and increasing the cross-sectional area convergence length.

The relationship between water level (including residual water level) and river discharge, governed by the damping equation, enables us to develop a new method for estimating fresh water discharge in estuaries on the basis of tidal water level observations via an inverse analytical model, which is actually a modified Manning equation accounting for the effects of residual water level slope and tidal damping in estuaries. The application to the Yangtze estuary shows that the proposed analytical approach is able to have a first-order estimation of fresh water discharge in estuaries, and therefore it is a particularly useful tool for water management in coastal areas. 


\section{Appendix A: Influence of river discharge on the friction term}

In case of negligible river discharge, the damping equation is given by (see Cai et al., 2012a)

$\delta=\frac{\mu^{2}}{1+\mu^{2}}\left[\gamma-\mu \lambda \chi\left(\frac{2}{3} \mu \lambda+\frac{8}{9 \pi}\right)\right]$.

To illustrate the influence of river discharge on the friction term, we introduce an artificial friction number $\chi_{\mathrm{r}}$ due to river discharge. When accounting for the effect of river discharge, the damping Eq. (A1) is modified as (see Cai et al., 2014)

$$
\begin{aligned}
\delta & =\frac{\mu^{2}}{\beta \mu^{2}+1}\left[\gamma \theta-\mu \lambda \chi\left(\frac{2}{3} \mu \lambda+\frac{8}{9 \pi}\right) \frac{\frac{2}{3} \mu \lambda \kappa_{1}+\frac{8}{9 \pi} \kappa_{2}}{\frac{2}{3} \mu \lambda+\frac{8}{9 \pi}}\right] \\
& =\frac{\mu^{2}}{\beta \mu^{2}+1}\left[\gamma \theta-\mu \lambda\left(\frac{2}{3} \mu \lambda+\frac{8}{9 \pi}\right) \chi_{\mathrm{r}}\right],
\end{aligned}
$$

where $\beta$ and $\theta$ are defined in Eq. (5) and the coefficients $\kappa_{1}$ and $\kappa_{2}$ are given by

$\kappa_{1}= \begin{cases}1+\frac{8}{3} \zeta \frac{\varphi}{\mu \lambda}+\left(\frac{\varphi}{\mu \lambda}\right)^{2} & \text { for } \varphi<\mu \lambda \\ \frac{4}{3} \zeta+2 \frac{\varphi}{\mu \lambda}+\frac{4}{3} \zeta\left(\frac{\varphi}{\mu \lambda}\right)^{2} & \text { for } \varphi \geq \mu \lambda\end{cases}$

$\kappa_{2}=\frac{3 \pi}{16} L_{1}-\frac{\pi}{8} \frac{L_{0} \zeta}{\mu \lambda}$.

As can be seen from Eqs. (A1) and (A2), the influence of fresh water discharge is basically that of increasing friction by a factor which is a function of $\varphi$. Expressing the artificial friction number as $\chi_{\mathrm{r}}=\kappa \chi$ provides an estimation of the correction of the friction term

$\kappa=\frac{\chi_{\mathrm{r}}}{\chi}=\frac{\frac{2}{3} \mu \lambda \kappa_{1}+\frac{8}{9 \pi} \kappa_{2}}{\frac{2}{3} \mu \lambda+\frac{8}{9 \pi}}$,

which is needed to compensate for the lack of considering fresh water discharge. It should be noted that both $\beta$ and $\theta$ are equal to unity if $\varphi=0$. For $\varphi>0$, the correction factors $\theta$ and $\beta$ have values smaller than unity, but are close to unity as long as $\zeta \ll 1$. Thus the influence of river discharge introduced by these parameters is less prominent than that of the friction term.

\section{Appendix B: Revisiting the Manning equation}

The momentum equation when written in a Lagrangian reference frame reads (see Savenije, 2005, 2012)

$$
\frac{\mathrm{d} V}{\mathrm{~d} t}+g \frac{\partial h}{\partial x}+g \frac{\partial z_{\mathrm{b}}}{\partial x}+g \frac{h}{2 \rho} \frac{\partial \rho}{\partial x}+g n^{2} \frac{V|V|}{R^{4 / 3}}=0,
$$

where $h$ is the water depth, $z_{\mathrm{b}}$ is bottom elevation, $\rho$ is the water density, $n$ is Manning's coefficient $(n=1 / K)$, and $R$ is the hydraulic radius.
For uniform steady flow in a prismatic channel, Eq. (B1) can be simplified as the well-known Manning equation by neglecting the first, the second and the fourth terms:

$V=\frac{1}{n} R^{2 / 3} S^{1 / 2}$,

where $S=-\partial z_{\mathrm{b}} / \partial x$ is the slope of the channel.

Hence the expression for river discharge is given by

$Q_{0}=A V=\frac{1}{n} A R^{2 / 3} S^{1 / 2}$

where $A$ is the cross-sectional area.

For steady flow when depth may vary along a short section of the channel (e.g. during a flood), the residual water level slope $(\partial h / \partial x)$ should be taken into account and Eq. (B1) reduces to

$\frac{\partial h}{\partial x}+\frac{\partial z_{\mathrm{b}}}{\partial x}+n^{2} \frac{V|V|}{R^{4 / 3}}=0$.

Consequently, the Manning equation (Eq. B2) is modified as

$V=\frac{1}{n} R^{2 / 3}\left(S-\frac{\partial h}{\partial x}\right)^{1 / 2}$,

while the river discharge becomes

$Q_{1}=Q_{0}\left(1-\frac{\partial h}{\partial x} \frac{1}{S}\right)^{1 / 2}$

In the Lagrangian reference frame, the continuity equation can be written as (see Savenije, 2005, 2012)

$\frac{\mathrm{d} V}{\mathrm{~d} t}=r_{\mathrm{S}} \frac{c V}{h} \frac{\mathrm{D} h}{\mathrm{~d} x}-c V\left(\frac{1}{b}-\frac{1}{\eta} \frac{\mathrm{d} \eta}{\mathrm{d} x}\right)$.

In a tidal region, it is noted that both depth and discharge change along the channel axis (i.e. varied unsteady flow). Thus, Eq. (B1) when combined with Eq. (B7) becomes (see Savenije, 2005, 2012)

$$
\begin{aligned}
r_{\mathrm{S}} \frac{c V}{h} \frac{\mathrm{d} h}{\mathrm{~d} x} & -c V\left(\frac{1}{b}-\frac{1}{\eta} \frac{\mathrm{d} \eta}{\mathrm{d} x}\right)+g \frac{\partial h}{\partial x}+g \frac{\partial z_{\mathrm{b}}}{\partial x}+g \frac{h}{2 \rho} \frac{\partial \rho}{\partial x} \\
& +g n^{2} \frac{V|V|}{R^{4 / 3}}=0 .
\end{aligned}
$$

An analytical expression for the tidal damping can be obtained by subtracting high-water and low-water envelopes while accounting for the effect of river discharge (Cai et al., 2014): in the downstream tide-dominated zone, where $U_{r}<v \sin (\varepsilon)$

$$
\begin{gathered}
\frac{1}{\eta} \frac{\mathrm{d} \eta}{\mathrm{d} x}\left(\theta-r_{\mathrm{s}} \frac{\varphi}{\sin (\varepsilon)} \zeta+\frac{g \eta}{c v \sin (\varepsilon)}\right)=\frac{\theta}{a}-f \frac{v}{\bar{h} c} \\
\left(\frac{2}{3} \sin (\varepsilon)+\frac{16}{9} \varphi \zeta+\frac{2}{3} \frac{\varphi^{2}}{\sin (\varepsilon)}+\frac{L_{1}}{6}-\frac{L_{0}}{9} \frac{\zeta}{\sin (\varepsilon)}\right),
\end{gathered}
$$


and in the upstream river discharge-dominated zone, where $U_{r} \geq v \sin (\varepsilon)$,

$$
\begin{aligned}
& \frac{1}{\eta} \frac{\mathrm{d} \eta}{\mathrm{d} x}\left(\theta-r_{\mathrm{s}} \frac{\varphi}{\sin (\varepsilon)} \zeta+\frac{g \eta}{c v \sin (\varepsilon)}\right)=\frac{\theta}{a}-f \frac{v}{\bar{h} c} \\
& \left(\frac{8}{9} \zeta \sin (\varepsilon)+\frac{4}{3} \varphi+\frac{8}{9} \frac{\varphi^{2}}{\sin (\varepsilon)} \zeta+\frac{L_{1}}{6}-\frac{L_{0}}{9} \frac{\zeta}{\sin (\varepsilon)}\right) .
\end{aligned}
$$

When river discharge dominates over tide $(\varphi \geq 1)$, it is noted that the coefficients $L_{0}$ and $L_{1}$ can be calculated according to Eq. (12). Substituting Eq. (12) into Eq. (B10) then yields a quadratic equation for the dimensionless river discharge $\varphi$ :

$\sigma_{1} \varphi^{2}+\sigma_{2} \varphi+\sigma_{3}=0$

with

$$
\begin{aligned}
\sigma_{1} & =-\frac{4}{3} \frac{f v a \zeta}{\bar{h} c \sin (\varepsilon)}, \\
\sigma_{2} & =\frac{1}{\eta} \frac{\mathrm{d} \eta}{\mathrm{d} x} \frac{r_{\mathrm{S}} a \zeta}{\sin (\varepsilon)}-2 \frac{f v a}{\bar{h} c} \\
& +\left(\frac{1}{\eta} \frac{\mathrm{d} \eta}{\mathrm{d} x} a-1\right) \frac{\sqrt{1+\zeta}-1}{\sin (\varepsilon)}, \\
\sigma_{3} & =-\frac{f v a}{\bar{h} c}\left[\frac{8}{9} \zeta \sin (\varepsilon)+\frac{2}{9} \frac{\zeta}{\sin (\varepsilon)}\right] \\
& -\frac{1}{\eta} \frac{\mathrm{d} \eta}{\mathrm{d} x} a\left[1+\frac{g \eta}{c v \sin (\varepsilon)}\right],
\end{aligned}
$$

where the unknown variables $\varepsilon, c, v$ can be calculated with the explicit equations (i.e. the phase lag equation, the celerity equation and the scaling equation in Table 2) for given water level observations.

Equation (B11) gives two solutions:

$$
\begin{gathered}
\varphi_{1}=\frac{-\sigma_{2}+\sqrt{\sigma_{2}^{2}-4 \sigma_{1} \sigma_{3}}}{2 \sigma_{1}}, \\
\varphi_{2}=\frac{-\sigma_{2}-\sqrt{\sigma_{2}^{2}-4 \sigma_{1} \sigma_{3}}}{2 \sigma_{1}},
\end{gathered}
$$

in which the first root is always negative since both $\sigma_{1}$ and $\sigma_{2}$ are always negative. Hence the positive solution for $\varphi$ can only be given by the second root, which can be rewritten as

$U_{r}=v \frac{-\sigma_{2}-\sqrt{\sigma_{2}^{2}-4 \sigma_{1} \sigma_{3}}}{2 \sigma_{1}}$.

We can see that Eq. (B16) is actually a modified Manning equation, accounting for friction and the effects of residual water level slope (i.e. $\mathrm{d} h / \mathrm{d} x$ implicitly included in the parameter of the cross-sectional area convergence $a$ since $\frac{1}{a}=\frac{1}{b}+\frac{1}{d}=-\frac{1}{\bar{B}} \frac{\mathrm{d} \bar{B}}{\mathrm{~d} x}-\frac{1}{\bar{h}} \frac{\mathrm{d} \bar{h}}{\mathrm{~d} x}$ ) and tidal damping (i.e. $\mathrm{d} \eta / \mathrm{d} x$ ). 


\section{The Supplement related to this article is available online at doi:10.5194/hess-18-4153-2014-supplement.}

Acknowledgements. The authors would like to thank David Jay and the other anonymous referee for their valuable comments and suggestions, which have greatly improved this paper. The first author was financially supported for his $\mathrm{Ph} . \mathrm{D}$. research by the China Scholarship Council with the project reference number of 2010638037.

Edited by: G. Blöschl

\section{References}

Buschman, F. A., Hoitink, A. J. F., van der Vegt, M., and Hoekstra, P.: Subtidal water level variation controlled by river flow and tides, Water Resour. Res., 45, W10420, doi:10.1029/2009WR008167, 2009.

Cai, H., Savenije, H. H. G., and Toffolon, M.: A new analytical framework for assessing the effect of sea-level rise and dredging on tidal damping in estuaries, J. Geophys. Res., 117, C09023, doi:10.1029/2012JC008000, 2012a.

Cai, H., Savenije, H. H. G., Yang, Q., Ou, S., and Lei, Y.: Influence of river discharge and dredging on tidal wave propagation; Modaomen estuary case, J. Hydraul. Eng., 138, 885-896, doi:10.1061/(ASCE)HY.1943-7900.0000594, 2012b.

Cai, H., Savenije, H. H. G., and Toffolon, M.: Linking the river to the estuary: nfluence of river discharge on tidal damping, Hydrol. Earth Syst. Sci., 18, 287-304, doi:10.5194/hess-18-2872014, 2014.

Dronkers, J. J.: Tidal computations in River and Coastal Waters, Elsevier, New York, 1964.

Erdal, H. I. and Karakurt, O.: Advancing monthly streamflow prediction accuracy of CART models using ensemble learning paradigms, J. Hydrol., 477, 119-128, doi:10.1016/j.jhydrol.2012.11.015, 2013.

Godin, G.: Modification of River Tides by the Discharge, J. Waterw. Port C-Asce, 111, 257-274, doi:10.1061/(ASCE)0733950X(1985)111:2(257), 1985.

Godin, G.: The propagation of tides up rivers with special considerations on the upper Saint Lawrence river, Estuar. Coast Shelf S., 48, 307-324, doi:10.1006/ecss.1998.0422, 1999.

Gong, W. P. and Shen, J.: The response of salt intrusion to changes in river discharge and tidal mixing during the dry season in the Modaomen Estuary, China, Cont. Shelf. Res., 31, 769-788, doi:10.1016/j.csr.2011.01.011, 2011.

Horrevoets, A. C., Savenije, H. H. G., Schuurman, J. N., and Graas, S.: The influence of river discharge on tidal damping in alluvial estuaries, J. Hydrol., 294, 213-228, doi:10.1016/j.jhydrol.2004.02.012, 2004.

Jay, D. A., Flick, R. E., and Kukulka, T.: A long-term San Francisco Bay inflow record derived from tides: defining the great flood of 1862, in: Fall AGU Meeting, GC13B-1228, 5-9 December 2005, San Francisco, 2005

Jay, D. A.: Green Law Revisited - Tidal Long-Wave Propagation in Channels with Strong Topography, J. Geophys. Res., 96, 2058520598, doi:10.1029/91JC01633, 1991.
Jay, D. A. and Flinchem, E. P.: Interaction of fluctuating river flow with a barotropic tide: A demonstration of wavelet tidal analysis methods, J. Geophys. Res., 102, 5705-5720, doi:10.1029/96JC00496, 1997.

Jay, D. A. and Kukulka, T.: Revising the paradigm of tidal analysisthe uses of non-stationary data, Ocean Dynam., 53, 110-125, doi:10.1007/s10236-003-0042-y, 2003.

Jay, D. A., Leffler, K., and Degens, S.: Long-Term Evolution of Columbia River Tides, J. Waterw. Port C-Asce, 137, 182-191, doi:10.1061/(ASCE)WW.1943-5460.0000082, 2011.

Kukulka, T. and Jay, D. A.: Impacts of Columbia River discharge on salmonid habitat: 1 . A nonstationary fluvial tide model, J. Geophys. Res., 108, 3293, doi:10.1029/2002JC001382, 2003a.

Kukulka, T. and Jay, D. A.: Impacts of Columbia River discharge on salmonid habitat: 2. Changes in shallow-water habitat, J. Geophys. Res., 108, 3294, doi:10.1029/2003JC001829, 2003b.

Leblond, P. H.: Tidal Propagation in Shallow Rivers, J. Geophys. Res., 83, 4717-4721, doi:10.1029/JC083iC09p04717, 1978.

Liu, Z., Zhou, P., Chen, G., and Guo, L.: Evaluating a coupled discrete wavelet transform and support vector regression for daily and monthly streamflow forecasting, J. Hydrol., doi:10.1016/j.jhydrol.2014.06.050, in press, 2014.

MacCready, P.: Estuarine adjustment, J. Phys. Oceanogr., 37, 2133 2145, doi:10.1175/JPO3082.1, 2007.

Madsen, H. and Skotner, C.: Adaptive state updating in real-time river flow forecasting - a combined filtering and error forecasting procedure, J. Hydrol., 308, 302-312, doi:10.1016/j.jhydrol.2004.10.030, 2005.

Moftakhari, H. R., Jay, D. A., Talke, S. A., Kukulka, T., and Bromirski, P. D.: A novel approach to flow estimation in tidal rivers, Water Resour. Res., 49, 4817-4832, doi:10.1002/wrcr.20363, 2013.

Prandle, D.: How tides and river flows determine estuarine bathymetries, Prog. Oceanogr., 61, 1-26, doi:10.1016/j.pocean.2004.03.001, 2004.

Savenije, H. H. G.: Analytical expression for tidal damping in alluvial estuaries, J. Hydraul. Eng., 124, 615-618, doi:10.1061/(ASCE)0733-9429(1998)124:6(615), 1998.

Savenije, H. H. G.: Salinity and Tides in Alluvial Estuaries, Elsevier, New York, 2005.

Savenije, H. H. G.: Salinity and Tides in Alluvial Estuaries, completely revised 2nd Edn., www.salinityandtides.com (last access: 20 May 2014), 2012.

Savenije, H. H. G., Toffolon, M., Haas, J., and Veling, E. J. M.: Analytical description of tidal dynamics in convergent estuaries, J. Geophys. Res., 113, C10025, doi:10.1029/2007JC004408, 2008.

Syvitski, J. P. M., Peckham, S. D., Hilberman, R., and Mulder, T.: Predicting the terrestrial flux of sediment to the global ocean: a planetary perspective, Sediment Geol., 162, 5-24, doi:10.1016/S0037-0738(03)00232-X, 2003.

Toffolon, M. and Savenije, H. H. G.: Revisiting linearized onedimensional tidal propagation, J. Geophys. Res., 116, C07007, doi:10.1029/2010JC006616, 2011.

Toffolon, M., Vignoli, G., and Tubino, M.: Relevant parameters and finite amplitude effects in estuarine hydrodynamics, J. Geophys. Res., 111, C10014, doi:10.1029/2005JC003104, 2006. 
Vignoli, G., Toffolon, M., and Tubino, M.: Non-linear frictional residual effects on tide propagation, in: Proceedings of XXX IAHR Congress, vol. A, 24-29 August 2003, Thessaloniki, Greece, 291-298, 2003.

Wang, Y. H., Ridd, P. V., Wu, H. L., Wu, J. X., and Shen, H. T.: Long-term morphodynamic evolution and the equilibrium mechanism of a flood channel in the Yangtze Estuary (China), Geomorphology, 99, 130-138, doi:10.1016/j.geomorph.2007.10.003, 2008.
Zhang, E. F., Savenije, H. H. G., Chen, S. L., and Chen, J. Y.: Water abstraction along the lower Yangtze River, China, and its impact on water discharge into the estuary, Phys. Chem. Earth, 47-48, 76-85, doi:10.1016/j.bbr.2011.03.031, 2012a.

Zhang, E. F., Savenije, H. H. G., Chen, S. L., and Mao, X. H.: An analytical solution for tidal propagation in the Yangtze Estuary, China, Hydrol. Earth Syst. Sci., 16, 3327-3339, doi:10.5194/hess-16-3327-2012, 2012b. 